\title{
A VALUE SENSITIVE ABM OF THE REFUGEE CRISIS IN THE NETHERLANDS
}

\author{
Ross Gore \\ Virginia Modeling, Analysis \\ $\&$ Simulation Center \\ Old Dominion University \\ Norfolk, VA, USA \\ ross.gore@gmail.com
}

\author{
F. LeRon Shults \\ NORCE Center for \\ Modeling Social Systems \\ University of Agder \\ Kristiansand, Norway \\ leron.shults@uia.no
}

\author{
Phillip Wozny \\ Frank P. M. Dignum \\ Department of Information \\ \& Computing Sciences \\ Universiteit Utrecht \\ Utrecht, Netherlands \\ phillipjw@gmail.com, f.p.m.dignum@uu.nl \\ Christine Boshuijzen - van Burken \\ Lamber Royakkers \\ Industrial Engineering \\ \& Innovation Sciences \\ Eindhoven University of Technology \\ Eindhoven, Netherlands \\ \{c.g.boshuijzen,l.m.m.royakkers\}@ @ue.nl
}

\begin{abstract}
We develop an agent based model to characterize the wellbeing of newcomers (i.e. asylum seeking refugees) in the context of asylum logistics using Schwartz's theory of values. The model produces recommendations for decision-makers with respect to avoiding catastrophic outcomes and maximizing best case outcomes. We conduct analysis to show that while a relatively simple set of conditions is necessary to avoid catastrophic outcomes, these conditions are insufficient to maximize the best case outcomes. Furthermore, the conditions that maximize one best case outcome do so at the expense of another. The result is a platform for decisionmakers to understand tradeoffs in policies for government and non-government organizations.
\end{abstract}

Keywords: agent-based model, simulation and policy, humanitarian logistics, refugees, Schwartz values

\section{INTRODUCTION}

A peaceful protest in Syria amidst the Arab Spring escalated into a civil war in which both state and armed non-state actors targeted civilian populations. This prompted forced migration resulting in 1.6 million people being displaced from Syria (Hatton 2017, Unhcr 2010). This kind of refugee influx is logistically problematic for both government and non-government organizations (NGOs) responsible for refugees (Papadaki 2017). Throughout the remainder of this paper we use the word newcomer in place of the word "refugee" for its political neutrality and because the word "refugee" denotes a specific legal status. A newcomer refers to one who recently arrived. We present an agent-based model to characterize the wellbeing of newcomers in the context of the refugee crisis asylum logistics using Schwartz's theory of values as a decision procedure 
and wellbeing operationalization. Our model shows that a relatively simple set of conditions is necessary to avoid catastrophic outcomes related to newcomer wellbeing and public opinion of newcomers. These simple conditions are: (1) the presence of a NGO within cities and (2) an understanding of the brands of activities in which newcomers will participate. In addition, these conditions are necessary but insufficient to maximize newcomer wellbeing and public opinion. Furthermore, the Schwartz values (discussed in depth in Section 2) of the government organization that is responsible for making the asylum decision (IND) are different depending on which outcome (newcomer wellbeing vs. public opinion) is maximized.

\section{BACKGROUND AND RELATED WORK}

Asylum Background: Our model simulates the Dutch asylum procedure. The key actors are newcomers, Central Orgaanopvang Asielzoekers (COA), Immigratie en Naturalisatiedienst (IND), and NonGovernmental Organization (NGOs). Figure 1 shows the asylum procedure. The procedure consists of housing newcomers as they move through the varying stages of the legal procedure; it proceeds as follows. Before obtaining a formal Asylum Seeker (AS) status, a newcomer who applies for refugee status has legal status Externally Displaced Person (EDP). The newcomer receives a health examination and registers as an asylum seeker at the Central Reception Location (COL). After two days, the newcomer is sent to a Process Reception Location (POL) facility where their legal status changes to AS and they begin the general asylum procedure. After an intake interview in the POL, IND repatriates newcomers from designated safe countries. If the newcomer appeals the decision or IND requires more time to decide, the newcomer is transferred to the Asylum Seeker Center (AZC) for the extended asylum procedure. Their accommodation and care is managed by COA, which tightly controls movement in and out of the AZC, and residents must report regularly (Bakker, Cheung, and Phillimore 2016). NGOs support newcomers both during and after the process by providing information, resources and organizing activities (VluchtelingenWerk 2016). The asylum procedure lasts from four to eight days. If refugee status is granted, an asylum seeker receives a residence permit, Temporary Residence (TR) status, for five years. Then, the COA supplies the newcomer with social housing nearby the AZC, which are typically in rural zones. With refugee status, one can receive social security benefits, enroll in a university, and work. They are then obligated to undergo an integration course on Dutch language and culture. After passing the exam, they are then qualified to apply to become a permanent Dutch resident (Bakker, Cheung, and Phillimore 2016). A more detailed discussion of the general Dutch asylum procedure is provided in (Wozny 2018).

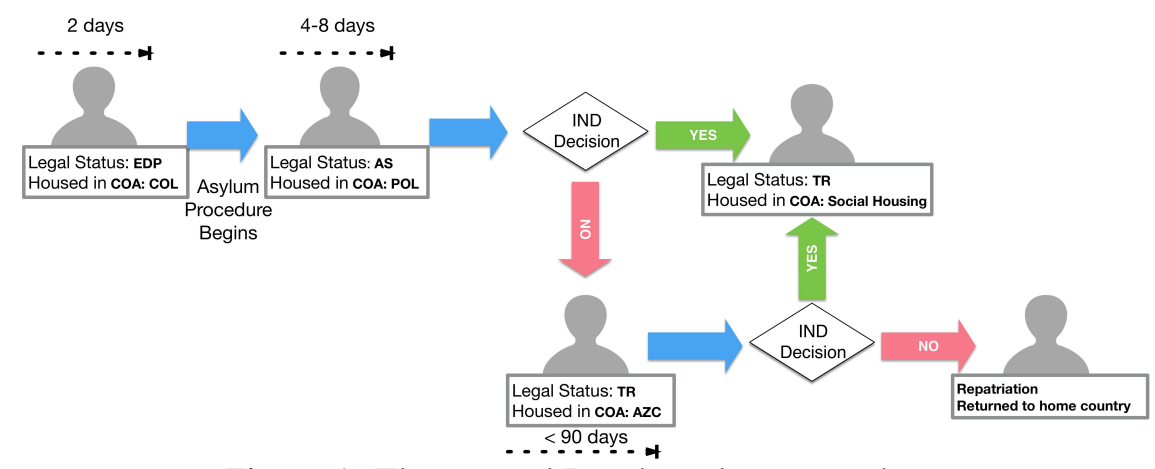

Figure 1: The general Dutch asylum procedure.

Schwartz Values Background: While the Dutch asylum procedure provides the logistical structure of the model it is complemented with Schwartz Values for the asylum seekers and key actors. Schwartz Values are abstract drivers of behavior that shape the way in which humans interact to survive and thrive. The ten Schwartz Values are presented in the inner circle of Figure 2 (Schwartz 2012). The placement of Schwartz Values in Figure 2 corresponds to their correlation. Any two Schwartz Value Quadrants (SVQs) opposite one another on the circle undermine each other's satisfaction. This reflects how the SVQs differ on two 
axes, the individual versus social dimension and the gain-approach versus loss-avoidance dimension. The four SVQs are defined as: (1) Self-Enhancement values strengthen an individual's condition and focus on loss-avoidance (in opposition of Self-Transcendence); (2) Openness-to-Change values imply an accommodation and pursuit of variance in terms of individual experience (in opposition of Conservation); (3) Self-Transcendence values place wellbeing of others above the wellbeing of the individual (in opposition of Self-Enhancement); and (4) Conservation values reinforce the status quo in a social manner that is focused on loss-avoidance (in opposition of Openness-to-Change).

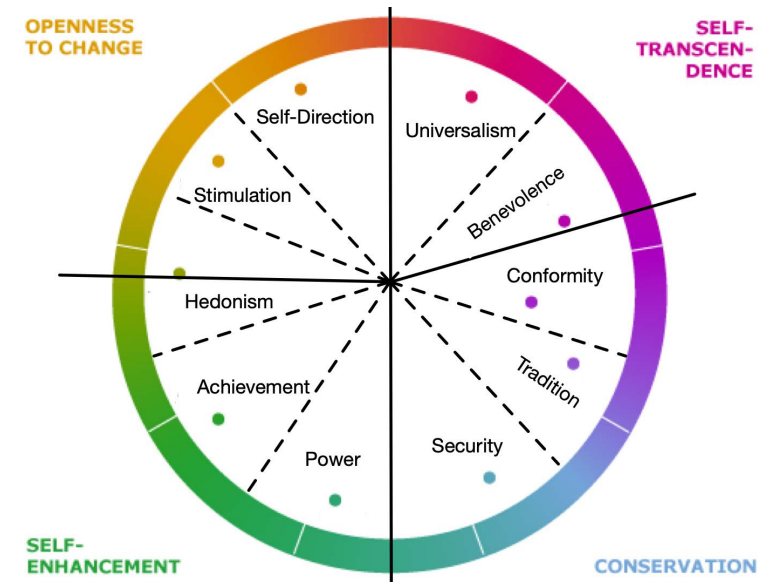

Figure 2: Circle of Schwartz's Theory of Values broken into quadrants.

Related Research: Several other ABMs have been developed to model bottom-up dynamics related to newcomers. Collins and Frydenlund built an ABM which models group formation during long distance movement (Collins and Frydenlund 2016). The model is a theoretical exploration that characterizes the process of flight from conflict as a payoff variable which slows down movement but increases security. Groen developed an ABM that simulates flight from violent conflict through a strictly movement oriented lens (Groen 2016). Similarly, Herbert et al. and Suleimenova et al. used different geo-spatially explicit ABMs to predict flight destinations following violent conflict (Hébert, Perez, and Harati 2018, Suleimenova, Bell, and Groen 2017). Unlike the previously mentioned movement models, which focused on movement within a single or small cluster of states, Hattle, Yang and Zeng applied a similar methodology to migration into Europe (Hatton 2017). Crooks and Hailegiorgis have developed a number of agent-based models of the spread of cholera within and between refugee camps (Crooks and Hailegiorgis 2014, Hailegiorgis and Crooks 2012). Anderson et al. have developed a health focused ABM that includes both newcomers and the institutions responsible for their care (Anderson, Chaturvedi, and Cibulskis 2007). The model includes a weighted set of desires in a manner similar to the inclusion of values in our model. However, our model implements values in a manner more consistent with the established Schwartz's theory of values (Wozny 2018). In addition, the model builds on the work of Silverman and Bharathy which explores modeling personality \& cognition at the agent level (Silverman and Bharathy 2005).

\section{MODEL}

Here we explain how Schwartz Values are implemented in the model, manifested by agents and operationalized into a measure of wellbeing. An ODD Protocol describing the model is available (Wozny 2018). 


\subsection{Schwartz Value Quadrants (SVQs) \& Agents}

The agents in our model have the four Schwartz Value Quadrants (SVQs) described in Section 2: Conservation, Self-Enhancement, Self-Transcendence, and Openness-to-Change. Each SVQ has a satisfaction threshold between $[0,100]$ indicating its importance to the agent. At any given point in time an agent has a current amount of each SVQ which decays uniformly over time. SVQs are satisfied by performing SVQ acts (activities for newcomers, actions for institutional agents). SVQ acts increment the agent's current amount of a given SVQ. An agent's SVQ is satisfied when the agent's current amount of the SVQ is $\geq$ than the agent's satisfaction threshold for the SVQ. The increment amount of a SVQ act is 100 - SVQ threshold. Thus, SVQs with higher satisfaction thresholds require the agent to take more SVQ acts since: (1) the SVQ threshold is high and (2) the high SVQ threshold creates a small SVQ act increment amount. When given an opportunity to choose what act to take an agent chooses the act that once taken will minimize the distance between the amount of the most deficient SVQ and the SVQ threshold. Figure 3 shows an example of this.

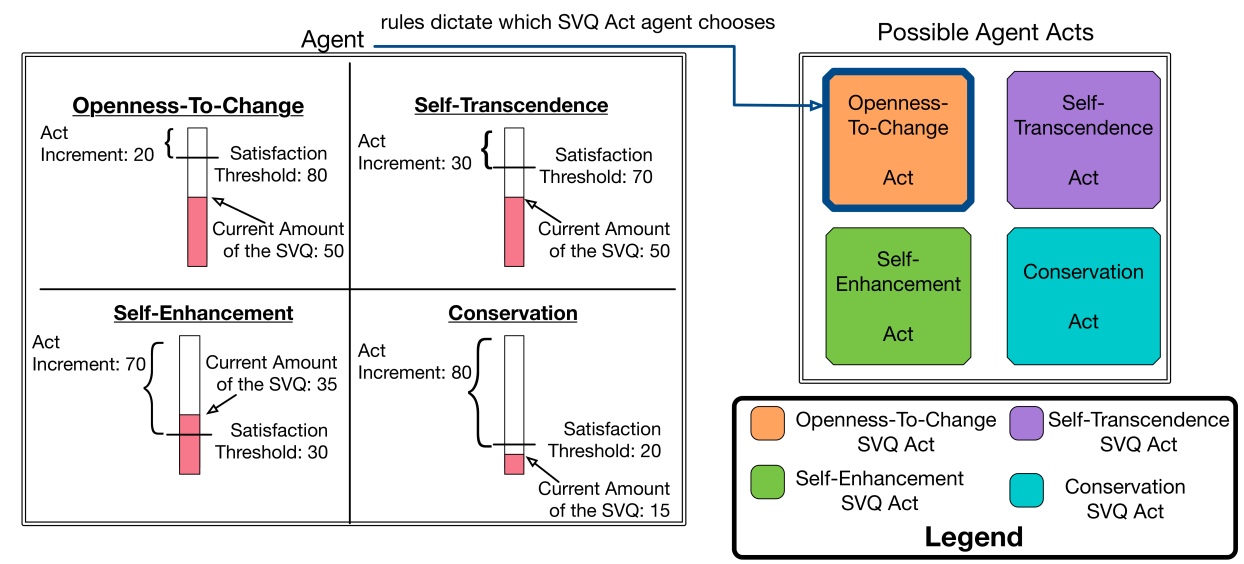

Figure 3: Implementation of Schwartz Value Quadrants (SVQs) within the model.

Within our model each type of agent has two possible classes of acts: (1) obligatory acts and (2) SVQ acts. Obligatory acts must be completed by the agent when required. SVQ acts are opportunities for the agent to satisfy their SVQs. Table 1 summarizes the obligatory and SVQ acts each agent can take.

Newcomers: Within our model newcomers navigate the general Dutch asylum process shown in Figure 1. This process is initiated through the obligatory newcomer agent activity IND Interview. During the IND Interview activity, the newcomer's documentation-quality increases. This represents the newcomer gathering documents to prove their case. Once the interview takes place the legal status of the newcomer is determined based on the actions of the IND government institutional agent. It is important to note that acts of newcomer agents in our model are activities and the acts of institutional agents, COA, NGOs and IND are actions. The distinction is made to contrast the fixed set of institutional actions and the changing set of newcomer activities. While both SVQ actions and SVQ activities satisfy SVQs, only newcomer activities have a certain weekly frequency such that the set of possible activities is temporally variable. Once a newcomer completes their interview s/he can participate in SVQ activities.

Activities made available by either the COA or the NGO include: (1) Custom Activities developed by the NGO, (2) Volunteer (requires NGO to be present), (3) Language Class (requires newcomer to be legal status TR), (4) Football, (5) Work and (6) Study. The values satisfied by these activities are shown in Table 1. Newcomers also have a health attribute. The value of a newcomer's health ranges between $[0,100]$ and is randomly distributed upon initialization. It represents the physical health of the newcomer and decays at a rate that depends on wellbeing (described next) and the health of the building in which the newcomer resides. Building health reflects a combination of the cleanness of the building and the extent to which the building 
Table 1: Agent Obligatory and SVQ Acts.

\begin{tabular}{|c|c|c|c|}
\hline Agent & SVQ / Obligatory & Name & Prerequisite \\
\hline \multirow[t]{9}{*}{ Newcomer } & Obligatory & IND Interview & Legal Status: EDP \& Paired w/ IND conducting Interview Newcomer \\
\hline & Obligatory & Doctor & Health $<30$ \\
\hline & Conservation & Language Class & Legal Status: TR \\
\hline & Self-Enhancement & Work & Legal Status: TR, AS \\
\hline & Self-Enhancement & Study & Legal Status: TR, AS \\
\hline & Self-Enhancement & Crime & Legal Status: TR, AS \& $40<$ Health $<50 \&$ Wellbeing $<5$ \\
\hline & Openness-To-Change & Football & Legal Status: TR, AS \\
\hline & Self-Transcendence & Volunteer & NGO present \\
\hline & Determined by NGO & Custom Activity & NGO present \\
\hline \multirow[t]{6}{*}{ COA } & Obligatory & Checkin Newcomer & Paired w/ Accommodation Change of Newcomer \\
\hline & Obligatory & Construct Accommodation & None \\
\hline & Conservation & Segregate & None \\
\hline & Self-Enhancement & Improve Facilities & None \\
\hline & Openness-To-Change & Adjust Staff & None \\
\hline & Self-Transcendence & Invest & None \\
\hline \multirow[t]{6}{*}{ IND } & Obligatory & Interview Newcomer & Paired w/ Newcomer Participating in IND Interview \\
\hline & Obligatory & Decide Newcomer & Paired w/ Legal Status Change of Newcomer \\
\hline & Conservation & Raise Threshold & None \\
\hline & Self-Enhancement & Issue Statement & None \\
\hline & Openness-To-Change & Lower Threshold & None \\
\hline & Self-Transcendence & Adjust Staff & None \\
\hline \multirow[t]{4}{*}{ NGO } & Conservation & Fundraise & NGO present \\
\hline & Self-Enhancement & Marketing Campaign & NGO present \\
\hline & Openness-To-Change & Custom Activities & NGO present \\
\hline & Self-Transcendence & Prioritize & NGO present \\
\hline
\end{tabular}

is maintained. All activities, except for crime, require the newcomer to have a certain level of health for participation. Newcomers can improve their health by either participating in the Football activity or taking part in the obligatory activity of going to the doctor. The model obligates newcomers to go to the doctor when their health falls below a critically low threshold. We operationalize wellbeing as: 100 - the average amount that a newcomer's four SVQs are not satisfied. Thus wellbeing is measured in a $[0,100]$ range where 0 reflects no value satisfaction in any SVQ and 100 reflects complete value satisfaction in all SVQs. Upon initialization newcomers are initialized with SVQ thresholds and SVQ amounts. Both the SVQ thresholds and the SVQ amounts are randomly distributed.

An additional activity that is always available to newcomers is Crime. Crime fulfills the Self-Enhancement SVQ. It can occur when: (1) the newcomer is very unsatisfied with respect to the Self-Enhancement SVQ and (2) the newcomer's wellbeing is extremely low (i.e. $\leq 5$ ). Even under these circumstances the newcomer does not necessarily participate in a Crime SVQ activity. A random distribution is sampled to determine if the newcomer will choose to participate. The result is that crime is a rare occurrence that is only manifested by newcomer's under specific circumstances. However, when a crime does occur it reduces the city residents' public-opinion of the management of newcomers. The Volunteer activity, on the other hand, which requires a NGO to be present, increases the city residents' public-opinion of the management of newcomers.

IND: The IND agent is responsible for updating the legal-status of a newcomer according to the newcomer's documentation-quality. The IND does this through two obligatory actions. The first obligatory action is Interview Newcomer which is coupled with the obligatory newcomer activity, IND Interview. IND's second obligatory action is to: (1) initially decide on a newcomer's asylum case or (2) decide on an appeal to a newcomer's case. IND has distinct thresholds for initial and appeal decisions. In both cases when the IND makes a decision it compares a newcomer's documentation-quality to a threshold such that positive decisions occur if the threshold is exceeded. IND's SVQ actions can influence the parameters of this process. IND's Conservation SVQ Action, Raise Threshold, increases the threshold on newcomer documentation-quality. This results in newcomers who possess sufficient documentation of their need for asylum being denied entry into the country. This type of IND decision error is referred to as a false negative because it is a result which 
incorrectly indicates that sufficient documentation quality for a newcomer is absent. When an IND false negative (FN) decision occurs the city residents' public-opinion of the management of newcomers decreases. IND's Self-Transcendent SVQ Action, Lower Threshold, works in exactly the opposite manner. Lower Threshold decreases the threshold on documentation quality resulting in IND false positive (FP) decision errors: a result which incorrectly indicates that sufficient documentation quality for a newcomer is present. When an IND FP decision error occurs the city residents' public-opinion of the management of newcomers decreases too. The remaining IND SVQ actions also relate to the decision process. The IND Openness-ToChange SVQ action, Increase Staff, provides additional staff at the IND which decreases the number of days a newcomer spends in the COL, POL and AZC facilities waiting to receive a decision from IND. The IND Self-Enhancement SVQ action, Issue Statement, reflects a press release from the government dissuading newcomers to come to the country. This reduces the overall number of newcomers in the population.

COA: COA is an institutional agent responsible for housing newcomers in the COL, POL, AZC and social housing depending upon where the newcomers are in the general asylum process. The COA also maintains the health of each of these buildings and staffs the buildings with COA employees. Both of the COA obligatory actions are related to managing accommodations of newcomers. The first obligatory action is to Check-in newcomers into their appropriate housing. The second obligatory action is to Construct Accommodation. This reflects COA building additional housing facilities for newcomers when its current housing supply is at capacity. COA's Conservation SVQ action is Segregate which separates newcomers who have yet to receive a final IND decision. When performing a Segregate action COA sends newcomers with poor document quality to housing locations with worse building health and newcomers with high document quality to housing locations with better building health. Recall a housing location's building health impacts the health of the newcomers that reside in it. COA's Self-Transcendence SVQ action is Invest. COA Invest provides a voucher to newcomers enabling them to travel to other cities to participate in a SVQ activity that better meets their SVQ needs. The COA Openness-To-Change SVQ action is Adjust Staff. COA Adjust Staff increases the staff in housing locations to ensure that newcomers are carefully monitored. More careful monitoring within a COA ensures that when travel vouchers are provided all newcomers receive one. In addition, careful monitoring ensures that newcomers whose health falls below the critical threshold visit the doctor. The Self-Enhancement SVQ action for COA is Improve Facilities. An Improve Facilities action results in COA repairing and providing maintenance to the COL, POL, AZC and social housing. The repairs and maintenance improve the health of these buildings which improves the health of the newcomers residing in them. Recall, COA also provides the following activities for newcomers depending on their legal status: (1) Language Class, (2) Football, (3) Work and (4) Study. These activities are scheduled on specific days of the week and that schedule does not change based on the SVQ needs of the newcomers.

NGO: NGO is a non-government institutional agent that supports newcomers through the development and scheduling of activities, raising funds from the public, and influencing the public. Unlike the other agents in our model, a NGO agent is not required to be present in cities and does not have any obligatory actions. The Conservation SVQ Action for a NGO is Fundraise. Fundraise converts the city residents' public-opinion of the management of newcomers into funds for the NGO to use in the future. The opposite of the Fundraise SVQ action for a NGO is the Self-Enhancement SVQ action, Marketing Campaign. When performing a marketing campaign a NGO converts funds into the city residents' public-opinion of the management of newcomers. The final two SVQ actions for a NGO are related to developing and scheduling newcomer activities. The Self-Transcendence SVQ action for a NGO is Custom Activities. When performing a Custom Activities action a NGO identifies the most unsatisfied SVQ among the newcomers in the city and develops an activity to satisfy it. Initially, the Custom Activity is scheduled for one session on a random day of the week. Every time a Custom Activity is developed the funds of the NGOs decrease. If a NGO does not have sufficient funds it cannot perform a Custom Activity action. The Openness-To-Change SVQ action for a NGO is Prioritize which adjusts the scheduling of Custom Activities in the city to best meet the current SVQ needs of the population. For example, suppose a NGO has a Custom Activity satisfying the Openness- 
To-Change SVQ and a Custom Activity satisfying Conservation held two days a week. However, the most unsatisfied SVQ of the majority of newcomers in the city is the Conservation SVQ. In this scenario, the NGO Prioritize SVQ action would decrease the number of days the Openness-To-Change Custom Activity is scheduled and increase the number of days the Conservation SVQ is scheduled.

\subsection{Model Parameters \& Execution}

The model allows the user to specify: (1) if NGOs will be present in the cities, (2) if the activities developed by NGOs during the Custom Activity SVQ action will be branded as activities newcomers will participate in and (3) if the activities developed by NGOs during the Custom Activity SVQ action will be developed with an understanding of the most unsatisfied SVQ of the newcomers within the city. The latter two parameters require additional explanation and reflect the level of understanding a NGO has of newcomers.

The branding of Custom Activities reflects the dissonance that is possible between a host country and newcomers. For example, the NGO may offer a Custom Activity satisfying Openness-To-Change in the form of a jewelry making class. However, even if the activity satisfies an unsatisfied SVQ for a newcomer, s/he may not participate in the class because of native cultural norms which require jewelry to be hidden.

The understanding of the most unsatisfied SVQ of newcomers parameter reflects the NGO understanding how, in terms of SVQs, newcomers are unsatisfied. This understanding effects how a NGO develops and schedules Custom Activities to satisfy these needs. If a NGO understands the most unsatisfied SVQ of a newcomer then Custom Activities are always developed to satisfy the most unsatisfied SVQ and Prioritize schedules those Custom Activities so that they help the most newcomers. If a NGO does not understand the most unsatisfied SVQ of a newcomer then Custom Activities and Prioritize scheduling are done at random.

The model also enables users to specify the initial city residents' public-opinion of the management of newcomers and explore different value parameterizations for the COA, NGO (if present) and IND. An overview of these parameters and the aforementioned parameters are shown in Table 2. Recall, each of the four values (Conservation, Self-Enhancement, Openness-to-Change and Self-Transcendence) are put on a [0-100] scale. In addition we apply the Schwartz's theory of values constraint that modifications in Conservation alter Openness-to-Change and modifications in Self-Enhancement alter Self-Transcendence.

Table 2: Model parameters.

\begin{tabular}{|lrr|}
\hline Parameter & Prerequisite & Value \\
\hline NGO Present In Cities & None & True / False \\
\hline NGO Custom Activities Branded Towards Newcomers & NGO Present & True / False \\
\hline NGO Understands Newcomer SVQs for Custom Activities \& Prioritization & NGO Present & True / False \\
\hline Initial Public Opinion in Cities & None & {$[0-100]$} \\
\hline COA Conservation & None & {$[20-80]$} \\
\hline COA Self-Enhancement & None & {$[20-80]$} \\
\hline COA Openness To Change & None & $100-$ COA Conservation \\
\hline COA Self-Transcendence & None & $100-$ COA Self-Enhancement \\
\hline NGO Conservation & NGO Present & [20-80] \\
\hline NGO Self-Enhancement & NGO Present & [20-80] \\
\hline NGO Openness To Change & NGO Present & 100-NGO Conservation \\
\hline NGO Self-Transcendence & NGO Present & $100-$ NGO Self-Enhancement \\
\hline IND Conservation & None & [20-80] \\
\hline IND Self-Enhancement & None & None \\
\hline IND Openness To Change & None & $100-$ IND Self-Enhancement \\
\hline IND Self-Transcendence & IND Conservation \\
\hline
\end{tabular}

Given a parameterization the model execution occurs through a series of time steps. In each step newcomers first identify any obligatory acts that are required in the time step. If any of these exist then the newcomer participates in the obligatory act and does not participate in any SVQ activities for the given time step. If no 
obligatory acts need to be performed then the newcomer identifies all SVQ activities that can be performed. This depends on the schedule of activities for the day, the health of the newcomer, the legal status of the newcomer, if the newcomer has been given a travel voucher by COA and if a NGO is present in their city. Next, COA and IND take any obligatory acts that are required in the time step. It is important to note that this does not preclude COA and IND from taking a SVQ action later in the time step. Then, all agents (newcomers, COA, NGO and IND) identify the available SVQ act which minimizes the distance between the amount of the most deficient SVQ and the SVQ threshold. Finally, the agent takes the SVQ act and updates its state variables. When an agent performs a SVQ act, the act directly effects other agents within the model. A visualization of these direct effects on newcomer wellbeing and city residents' public-opinion of the management of newcomers is shown in Figure 4. Not shown in Figure 4 are indirect effects that can occur within the model with respect to these two outcomes. Direct and indirect effects of acts on other outcomes are also not shown. Model execution terminates after 1,000 time steps ( 1 time step $=1$ day). This reflects $\sim 3$ years of time passing where a "steady state" when direct and indirect effects of the model parameters on the agents and the effects of the agents actions on one another have stabilized.

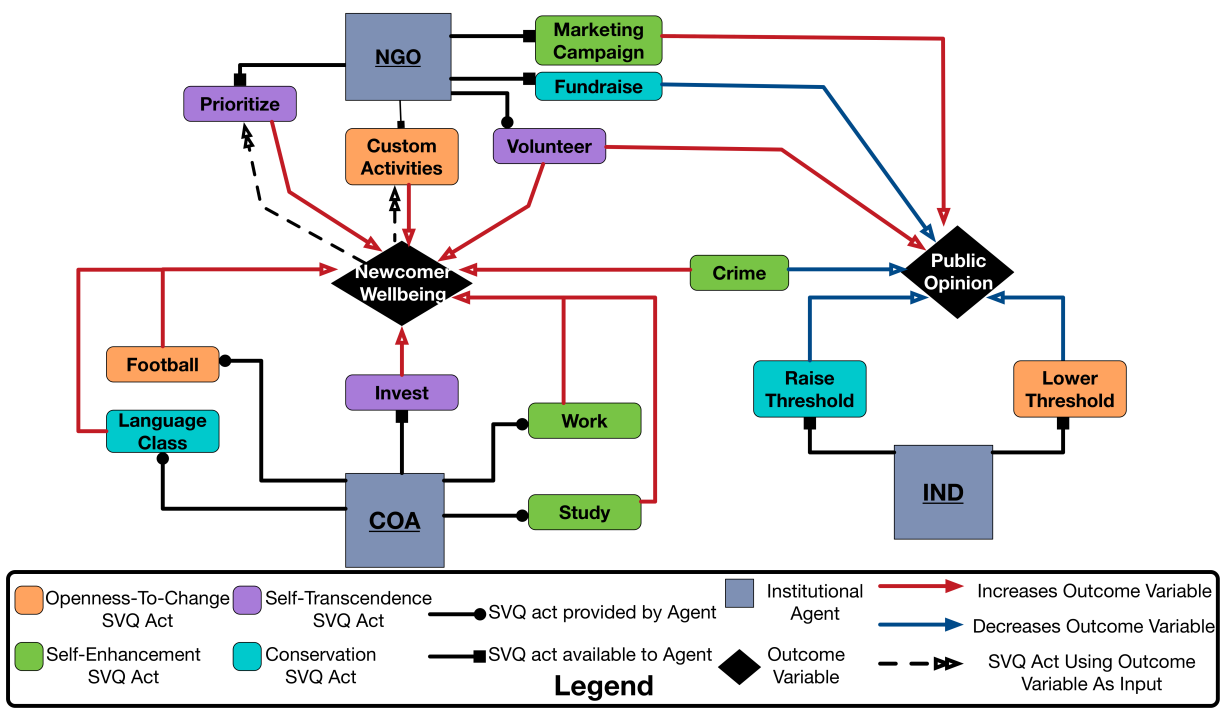

Figure 4: Direct effects on newcomer wellbeing and public opinion of management of newcomers.

\section{MODEL ANALYSIS}

To identify the conditions in the simulation that have the biggest effect on the two outcomes shown in Figure 4 we use a technique designed for analyzing agent-based models (Gore, Lynch, and Kavak 2017). We provide an overview of this analysis technique here, but it is described in more detail in (Gore, Reynolds Jr, Kamensky, Diallo, and Padilla 2015). It captures data throughout execution (i.e., records a trace of the execution) and uses the data to automatically generate conditions pertaining to the input parameters (Gore, Diallo, Lynch, and Padilla 2017). These generated conditions may be compound, which means that they are combined with logical operations. The conditions are used to quantify the extent to which combinations of agent and model characteristics cause an outcome of interest (i.e. newcomer wellbeing or city residents' public-opinion of the management of newcomers). We employ this technique to explore four research questions: (1-2) what conditions minimize and maximize newcomer wellbeing and (3-4) what conditions minimize and maximize city residents' public-opinion of the management of newcomers. The terms minimize and maximize reflect outcomes value 0 and 100 respectively.

The extent to which each generated condition causes an outcome is quantified by two measures: correlation (Corr) and coverage (Cov). These measures are aggregated into a single score called suspiciousness. The 
formulas for each measure are provided in (Diallo, Gore, Lynch, and Padilla 2016). The correlation measure captures the likelihood that, given the condition, the identified outcome (i.e. newcomer wellbeing $=$ 100) occurs. The coverage measure is the percentage of all traces in which the identified outcome occurs (i.e. newcomer wellbeing $=100$ ) that exhibit the specified condition. The suspiciousness (Susp) measure combines the correlation and the coverage measures. The correlation and coverage measure each have a maximum value of 1.0 and a minimum value of 0.0 . A suspiciousness value of 1.0 means that the condition is only true in traces in which the identified outcome occurs and the condition is true in all traces in which the identified outcome occurs. The existence of such a condition is not guaranteed. However, conditions with higher suspiciousness scores will provide more separation between the identified outcome and other related outcomes than conditions with lower suspiciousness scores. Our approach scores each condition generated using data captured during a sweep of the parameters in Table 2.

Table 3: Research Questions \& Associated Conditions w/ Highest Suspiciousness Scores.

\begin{tabular}{|c|c|c|c|c|}
\hline Research Question (RQ) & Condition & Susp & Corr & Cov \\
\hline $\begin{array}{l}\text { 1: Minimize Newcomer Wellbeing } \\
\text { Newcomer Wellbeing }=0\end{array}$ & $\begin{array}{l}\text { NGO Present In Cities = False OR } \\
\text { (NGO Present In Cities = True AND } \\
\text { NGO Custom Activities Branded Towards Newcomers = False) }\end{array}$ & 1.00 & 1.00 & 1.00 \\
\hline $\begin{array}{l}\text { 2: Maximize Newcomer Wellbeing } \\
\text { Newcomer Wellbeing }=100\end{array}$ & $\begin{array}{l}\text { NGO Present In Cities = True AND } \\
\text { NGO Custom Activities Branded Towards Newcomers AND } \\
\text { NGO Understands Newcomer SVQs for Custom Activities \& Prioritization = True AND } \\
\text { Initial Public Opinion in Cities }>80 \text { AND } \\
\text { NGO: Openness-To-Change }>70 \text { AND Conservation }<30 \text { AND } \\
\quad \text { Self-Transcendence }>70 \text { AND Self-Enhancement }<30 \\
\text { COA: Openness-To-Change }>70 \text { AND Conservation }<30 \text { AND } \\
\quad \text { Self-Transcendence }>\text { Self-Enhancement } \\
\text { IND : Openness-To-Change }>70 \text { AND Conservation }<30 \text { AND } \\
\quad \text { Self-Transcendence }>70 \text { AND Self-Enhancement }<30\end{array}$ & 0.85 & 1.00 & 0.74 \\
\hline $\begin{array}{l}\text { 3: Minimize Public Opinion } \\
\text { Public Opinion }=0\end{array}$ & $\begin{array}{l}\text { NGO Present In Cities }=\text { False OR } \\
\text { (NGO Present In Cities = True AND } \\
\text { NGO Custom Activities Branded Towards Newcomers = False) }\end{array}$ & 1.00 & 1.00 & 1.00 \\
\hline $\begin{array}{l}\text { 4: Maximize Public Opinion } \\
\text { Public Opinion }=100\end{array}$ & $\begin{array}{l}\text { NGO Present In Cities }=\text { True AND } \\
\text { NGO Custom Activities Branded Towards Newcomers AND } \\
\text { NGO Understands Newcomer SVQs for Custom Activities \& Prioritization = True AND } \\
\text { Initial Public Opinion in Cities }>80 \text { AND } \\
\text { NGO: Openness-To-Change }>70 \text { AND Conservation }<30 \text { AND } \\
\quad \text { Self-Transcendence }>70 \text { AND Self-Enhancement }<30 \\
\text { COA: Openness-To-Change }>70 \text { AND Conservation }<30 \text { AND } \\
\quad \text { Self-Transcendence }>\text { Self-Enhancement } \\
\text { IND : Openness-To-Change = Conservation AND } \\
\quad \text { Self-Transcendence = Self-Enhancement }\end{array}$ & 0.91 & 1.00 & 0.83 \\
\hline
\end{tabular}

Analysis of Research Question \#1: The rationale of this question is to identify those conditions that create a worst case scenario with respect to newcomer wellbeing so the identified conditions can be avoided by decision-makers. The compound condition with the top suspiciousness score is shown in Table 3. The correlation and coverage scores of the condition are also shown. These scores show that minimal newcomer wellbeing occurs when either: (1) no NGO is present in cities or (2) a NGO is present but the Custom Activities provided by the NGO are not branded towards newcomers. Recall, this latter condition means that even though the NGO is developing Custom Activities, newcomers are not interested in participating in them. As a result, the NGO SVQ actions Custom Activities and Prioritize have no effect on newcomer wellbeing. It is important to note that the NGO understanding of newcomer SVQs in generating Custom Activities and Prioritization is not identified. Thus the recommendation of our model to decisions makers is: NGOs should develop Custom Activities that newcomers will participate in, even if those activities are developed without an understanding of unsatisfied newcomer SVQs.

Analysis of Research Question \#2: The rationale of this question is to identify those conditions that create a best case scenario with respect to newcomer wellbeing so decision makers can pursue the identified conditions. The compound condition with the top suspiciousness score is shown in Table 3. The corre- 
lation and coverage score of the conditions are also shown in the table. The results show that maximum newcomer wellbeing is produced through a more subtle set of conditions than those that avoid minimum newcomer wellbeing. While the presence of a NGO in cities and an understanding of the Custom Activities that newcomers will participate in is required to maximize newcomer wellbeing; these conditions alone are not sufficient. Maximum newcomer wellbeing also requires: (1) high initial resident public-opinion of the management of newcomers in the city, (2) an understanding of unsatisfied newcomer SVQs for Custom Activities and Prioritization and (3) COAs, NGOs and INDs that are higher in Self-Transcendence and Openness-to-Change SVQs than Conservation and Self-Enhancement SVQs.

There are several important takeaways for decision-makers from the results of this analysis. The first is that while it is not important for NGOs to understand the SVQ needs of newcomers to avoid the minimum wellbeing, to provide maximum wellbeing NGOs must understand these needs. Similarly, while the initial city residents' public-opinion of the management of newcomers can be disregarded if the goal is to avoid the minimum newcomer wellbeing, it is a necessary for initial public opinion of the management of newcomers to be high to produce maximum newcomer wellbeing. Both of these conditions optimize the actions of NGOs in orthogonal ways to maximize their impact on newcomer wellbeing. Understanding the value needs of newcomers enables NGOs to develop Custom Activities that newcomers will participate in which satisfy their most unmet SVQ. The presence of cities with high public opinion of newcomers creates an environment for NGOs to effectively Fundraise and then convert those funds into several different Custom Activities operating on a dynamic schedule via Prioritize to address the most unmet SVQ of newcomers.

A NGO with SVQs that are higher in Self-Transcendence and Openness-To-Change than Self-Enhancement and Conservation is also required. Since public opinion is initially high, sporadic Fundraise SVQ actions are effective and Marketing Campaign SVQs actions are unnecessary. Instead, the bulk of the actions are spent on developing Custom Activities and scheduling them via Prioritize so newcomer SVQ needs are met.

The described environment also requires a COA with values that are higher in Self-Transcendence and Openness-to-Change SVQs than Self-Enhancement and Conservation. A COA with the described SVQs more often: (1) provides vouchers to newcomers to travel to cities with activities that best satisfy their unmet SVQs (2) and employs sufficient staff to ensure newcomers receive the vouchers, than the alternative SVQ actions. It is important to note that there is more balance in the COA Self-Transcendence and Self-Enhancement SVQs than the COA Openness-To-Change and Conservation SVQs. This occurs because when COA semi-regularly performs an Improve Facilities SVQ action (Self-Enhancement) it improves living accommodations which benefit the health of newcomers. These actions keep newcomers sufficiently healthy to participate in SVQ activities which promote wellbeing. An IND with the similar SVQs to the NGO and the COA also help maximize newcomer wellbeing. An IND that is high in the Openness-toChange and Self-Transcendence SVQs is well staffed and lenient in terms of the quality of documentation that is required during the asylum procedure. The result is that the length of the asylum procedure is extremely short because of the high number of staff members and the relative infrequency of a second decision from IND even being needed. These conditions lower the occupancy rate at the COL, POL and AZC which results in better building health at these locations and thus better health for newcomers. Recall, better health enables newcomers to participate in more activities to satisfy their unmet SVQs which promote wellbeing. However, maximizing newcomer wellbeing in this manner comes at a cost to public opinion (see RQ \#4).

Analysis of Research Question \#3: The rationale behind this question is to identify those conditions that create a worst case scenario for city residents' public-opinion of the management of newcomers so it can be avoided. The results, shown in Table 3, match the results for Research Question \#1. In other words, the same conditions that produce extremely low newcomer wellbeing also produce extremely low public opinion from residents in cities. These two outcomes are indirectly coupled in our model through the newcomer SVQ activity Crime. As the wellbeing of newcomers begins to approach zero newcomers begin to choose the SVQ Self-Enhancement activity Crime more frequently. When a newcomer crime occurs the 
public opinion of newcomers in the city is halved. Thus, those conditions that create minimal newcomer wellbeing, maximize the rate at which newcomer's participate in the SVQ activity Crime which results in the lowest city residents' public-opinion of the management of newcomers. It is noteworthy that the initial city residents' public-opinion of the management of newcomers is not identified. The recommendation of our model to decision makers it that it is important to encourage NGOs to come to cities with newcomers even if city residents' current public-opinion of the management of newcomers is very low.

Analysis of Research Question \#4: The rationale behind this question is to identify those conditions that create a best case scenario for city residents' public-opinion of the management of newcomers. The compound condition with the top suspiciousness score is shown in Table 3. These match the conditions that yield extremely high newcomer wellbeing in Research Question \#2 with one important distinction: to maximize public opinion an IND that is balanced in Conservation/Openness-to-Change and Self-enhancement/Selftranscendence SVQs is needed. This balanced IND is not overly strict or lenient with respect to newcomer documentation quality. Recall, the IND needed to maximize newcomer wellbeing was lenient. The leniency of that IND created a significant number of FP decision errors. Each FP decision error reduced city residents' public-opinion of the management of newcomers. The balanced IND in Research Question \#4 generates very few FP or FN decision errors. In comparison with Research Question \#2 there is not a decrease in public opinion due to the IND decision errors. However, in Research Question \#4 newcomers have a longer stay with higher occupancy in the COL, POL and AZC living accommodations. The higher occupancy and longer stay decreases building health, which decreases newcomer health which reduces the extent to which newcomers can participate in activities which satisfy their unmet SVQs. The identified conditions maximize public opinion at the expense of newcomer wellbeing. A statistical metamodel which elucidates this tradeoff in the two outcomes of our ABM can be explored at https://rgore-vmasc.shinyapps.io/integration-model/.

\section{CONCLUSION}

In this paper we described and analyzed an agent based model to characterize the wellbeing of newcomers in the context of asylum logistics using Schwartz's theory of values as a decision procedure and wellbeing operationalization. The model produces policy relevant insights for decision-makers with respect to newcomer wellbeing and the public opinion. A relatively simple set of conditions is necessary to avoid catastrophic outcomes but is insufficient to maximize the outcomes. Furthermore, the conditions that maximize one outcome do so at the expense of the other outcome. When the government organization that is responsible for making the asylum decision (IND) frequently takes actions which satisfy the Openness-To-Change and Self-Transcendence Schwartz Value Quadrants and rarely takes actions which satisfy the Conservation and Self-Enhancement Schwartz Value Quadrants, newcomer wellbeing is maximized. In contrast, when the IND performs actions with the same frequency across all four quadrants public opinion is maximized.

\section{ACKNOWLEDGMENTS}

This work is part of the research program Responsible Innovation with project number MVI.16.011, which is (partly) financed by the Netherlands Organisation for Scientific Research (NWO).

\section{REFERENCES}

Anderson, J., A. Chaturvedi, and M. Cibulskis. 2007. "Simulation tools for developing policies for complex systems: Modeling the health and safety of refugee communities". Health care management science vol. 10 (4), pp. 331-339.

Bakker, L., S. Y. Cheung, and J. Phillimore. 2016. "The asylum-integration paradox: Comparing asylum support systems and refugee integration in Europe". International Migration vol. 54 (4), pp. 118-132. 
Collins, A. J., and E. Frydenlund. 2016. "Agent-based modeling and strategic group formation: a refugee case study". In Proceedings of the 2016 Winter Simulation Conference, pp. 1289-1300. IEEE Press.

Crooks, A. T., and A. B. Hailegiorgis. 2014. "An agent-based modeling approach applied to the spread of cholera". Environmental Modelling \& Software vol. 62, pp. 164-177.

Diallo, S. Y., R. Gore, C. J. Lynch, and J. J. Padilla. 2016. "Formal methods, statistical debugging and exploratory analysis in support of system development: Towards a verification and validation calculator tool". International Journal of Modeling, Simulation, and Scientific Computing vol. 7 (01), pp. 1641001.

Gore, R., P. F. Reynolds Jr, D. Kamensky, S. Diallo, and J. Padilla. 2015. "Statistical debugging for simulations". ACM Transactions on Modeling and Computer Simulation (TOMACS) vol. 25 (3), pp. 16.

Gore, R. J., S. Diallo, C. Lynch, and J. Padilla. 2017. "Augmenting bottom-up metamodels with predicates". Jasss: The Journal of Artificial Societies and Social Simulation vol. 20 (1).

Gore, R. J., C. J. Lynch, and H. Kavak. 2017. "Applying statistical debugging for enhanced trace validation of agent-based models". Simulation vol. 93 (4), pp. 273-284.

Groen, D. 2016. "Simulating refugee movements: Where would you go?".

Hailegiorgis, A., and A. T. Crooks. 2012. "Agent-based modeling for humanitarian issues: disease and refugee camps". In The Computational Social Science Society of America Conference, Santa Fe, NM.

Hatton, T. J. 2017. "Refugees and asylum seekers, the crisis in Europe and the future of policy". Economic Policy vol. 32 (91), pp. 447-496.

Hébert, G. A., L. Perez, and S. Harati. 2018. "An ABM to Identify Migration Pathways of Refugees: The Case of Syria". In ABMs and Complexity Science in the Age of Geospatial Big Data, pp. 45-58. Springer.

Papadaki, S. 2017. "Refugees: The humanitarian logistics of a crisis situation". Master's thesis, International Hellenic University, Greece.

Schwartz, S. H. 2012. "An overview of the Schwartz theory of basic values". Online readings in Psychology and Culture vol. 2 (1), pp. 11.

Silverman, B. G., and G. K. Bharathy. 2005. "Modeling the personality \& cognition of leaders".

Suleimenova, D., D. Bell, and D. Groen. 2017. "A generalized simulation development approach for predicting refugee destinations". Scientific reports vol. 7 (1), pp. 13377.

Unhcr 2010. "Statistical Yearbook 2009: Trends in Displacement, Protection and Solutions".

VluchtelingenWerk 2016. "Dutch Council for Refugees - About Us". https://www.vluchtelingenwerk.nl/ artikel/dutch-council-refugees. Accessed: 2018-09-10.

Wozny, P. 2018. "A Value Sensitive Agent Based Simulation of the Refugee Crisis in the Netherlands". Master's thesis, Universiteit Utrecht, The Netherlands.

\section{AUTHOR BIOGRAPHIES}

ROSS GORE is a research assistant professor at VMASC. His email is ross.gore@ gmail.com.

PHILLIP WOZNY recently completed his Masters of Science. His email is phillipjw@ gmail.com.

FRANK P.M. DIGNUM is an associate professor at Utrecht University. His email is f.p.m.dignum@uu.nl.

F. LERON SHULTS directs the NORCE Research Institute. His email is leron.shults@uia.no.

CHRISTINE BOSHUJZEN-VAN BURKEN is a postdoc researcher. Her email is c.g.boshuijzen@tue.nl.

LAMBER ROYAKKERS is an associate professor at TU/e. His email is 1.m.m.royakkers@tue.nl. 